\title{
Experimental Characterization for Modelling of Turbocharger Friction Losses
}

\author{
Nicolas Perrot, Pascal Chesse, Rémi Dubouil, and Guillaume Goumy \\ Ecole Centrale De Nantes
}

\begin{abstract}
Today turbochargers are used by car manufacturers on Diesel engines and on an increasing number of gasoline engines, especially in the scope of downsizing. This component has to be well understood and modeled as simulation is widely used at every step of the development. Indeed development cost and time have to be reduced to fulfill both customers' wishes and more stringent emissions standards. Current turbocharger simulation codes are mostly based on look-up tables (air mass flow and efficiency) given by manufacturers. This raises two points. Firstly, the characteristics are known only in the same conditions as manufacturers' tests. Secondly, the turbine efficiency given by turbochargers manufacturers is the product of the isentropic efficiency and the turbocharger mechanical efficiency. This global efficiency is suitable for the calculation of the power transferred to the compressor. But the isentropic efficiency has to be determined to calculate the turbine outlet temperature, in parallel with heat transfers consideration. This implies to evaluate the mechanical efficiency. Most of the time, although experiments show this is not true, users make the hypothesis of a constant value. This assumption has a strong impact on the turbine outlet temperature and, as a consequence, on the modeled after treatment devices' light off. This article will present a study for characterization and modelling of turbocharger friction losses. First a specific experimental campaign is conducted on a test bench using a standard automotive turbocharger.

To eliminate the influence of thermal transfers, an adiabatic measurement methodology was developed. A second test campaign is performed with a modified turbocharger. It is based on the moment of inertia. The influence of oil viscosity was tested by using three different oil grades. The influence of oil inlet temperature and pressure was also tested to characterize the friction power. Finally a synthesis is made and hints are given in the view to generate a $0 \mathrm{D} / 1 \mathrm{D}$ turbocharger friction model.
\end{abstract}

\section{Introduction}

Transport is an important contributor to the pollutants and carbon dioxide emissions. In order to reduce fuel consumption and $\mathrm{CO} 2$ emissions, car manufacturers have generalized the use of turbochargers (TC) on internal combustion engines. Enabling a higher cylinder charge, they allow downsizing for instance. Moreover, drivability can be improved by generating the engine torque at lower engine speed. Nowadays turbochargers are widely used for LCV and passenger cars: compression ignition engines are almost always turbocharged and an increasing number of spark ignition engines are equipped with such a device.

Furthermore, targets of development cost and time reductions, quality requirements and the increasing complexity of engines drive the car manufacturers to use modelling and simulation in all the development, validation (MIL, HIL) and tuning phases. A good understanding of turbochargers laws is then necessary to define a reliable model.

The turbocharger is composed of a turbine and a compressor linked via a transmission shaft (in a central housing). Although ball bearings offer many advantages such as less friction torque and cold start engine performance improvement, see Zhang \& al.[1], the shaft is most of the time guided by oil bearings today: two journal bearings for rotation and one thrust bearing to compensate for the axial force imbalance.

The commonly used formula for the mechanical efficiency is the compressor / turbine mechanical powers ratio:

$$
\eta_{m e c}=\frac{P_{\text {mec } c p r}}{P_{\text {mec turb }}}
$$

As for the turbine, compressor enthalpy flow rate is used by manufacturer to calculate the efficiency:

$$
\eta_{\text {turb manuf }}=\frac{P_{\text {mec cpr }}}{P_{\text {turb isent }}}
$$

The isentropic turbine efficiency can be calculated from the two above equations: 


$$
\eta_{\text {turb isent }}=\frac{\eta_{\text {turb manuf }}}{\eta_{\text {mec }}}=\frac{P_{\text {mec turb }}}{P_{\text {turb lsent }}}
$$

The mechanical efficiency, eq. (1), is commonly considered constant and close to one in commercial simulation codes. This is not the case, especially in the low speed area [2] \& [3] , where the compressor power decreases. This range is used for instance in urban driving conditions. Thus this is a critical point with today normative cycles (e.g.: urban part of NEDC) and will remain an important topic for future cycles (RDE ...), which are more representative of real life conditions. Moreover more stringent emissions constraints will require more precise models. In low speed range, the friction power can then be equivalent to the compressor one and a slight variation of the former will have a noticeable impact on the mechanical efficiency, see Deligant \& al. [4]. Moreover, turbine efficiency provided by manufacturers, eq. (2), merges the turbine isentropic efficiency, eq. (3), heat transfers and the mechanical efficiency. The maps are measured for high turbine inlet temperature, which prevents from dissociating the two effects (thermal transfers, mechanical losses) only using the manufacturer data. Some models of thermal transfers in a turbocharger have been developed [5] as methods to extrapolate the manufacturer maps []]. A mechanical efficiency model will then enable to use and model the manufacturer turbine efficiency in the whole TC operating range. This article will present experimental techniques and results to characterize the friction losses in a turbocharger. This will generate a database and an influence parameter list to develop a friction losses model.

\section{Different Methods for Friction Losses Measurement}

First approach to estimate the mechanical losses is to understand and model the bearings behavior. Shi [7] modeled the floating bearings behavior, using Couette and Poiseuille equations. This leads to several complex equations which are not compatible with real time calculation for instance. Then several studies have been performed to define the influence parameters and to model directly the mechanical efficiency. Direct measurement of the friction torque on the TC itself during operation is difficult. Hence, different methods have been used to evaluate the friction torque and power based on direct and indirect measurements.

Deligant \& al. [4] used a dedicated test bench, developed in CNAM [8] in which a rotating torquemeter was introduced between a drive (a turbine for instance) and the transmission shaft equipped with bearings. This was completed with a magnetic axial force device which allowed studying the contribution of thrust and journal bearing losses to the overall friction losses. The precision and the reachable range depend both on the torquemeter characteristics. The study was focused on low TC speeds (up to $100000 \mathrm{rpm}$ ). Vanhaelst [9] also used a dedicated turbocharger driving test bench. The drive is a brushless electrical engine which is coupled to the turbocharger via a clutch. The advantage is to keep turbocharger integrity and to be able to study the thrust force influence. Moreover, it allows another direct measure, which consists in driving the turbocharger and release it suddenly (by disengaging the clutch), while measuring the time for the turbocharger to stop. Finally, other methods such as shaft displacement measurements were used to calculate the thrust bearing part in frictional losses [10].

The friction losses can also be estimated via measurements of other variables and assuming some hypothesis. The first method is based on oil enthalpy variation. In order to use this method, two assumptions have to be made:

- There is no heat exchange inside the turbocharger

- All the friction power is dissipated in the oil flow

The friction power can then be written as in equation (4):

$$
P_{f}=P_{o i l}=q_{m \text { oil }} \times c_{o i l} \times\left(T s_{o i l}-T e_{o i l}\right)
$$

This methodology was used for instance by Serrano \& al. [11] and by Marelli \& al. [12]. A quasi adiabatic test campaign was performed, and an additional term was added to take into account the convective heat flow from central housing to oil and vice versa. This term should be very small in comparison with the right term of the eq. (4), unless the hypothesis is wrong. In this case, a thermal transfer term has to be added [13]

The second "thermodynamic based" method consists in calculating the power delivered by the turbine and the one consumed by the compressor. The calculation is based on inlet and outlet temperatures of the studied component, cf. equations (5) and (6). Assuming the two above mentioned hypothesis, the difference between the two calculated powers equals the friction power, eq. (7).

$$
\begin{gathered}
P_{\text {turb }}=q_{\text {mair turb }} \times c_{p \text { air }} \times\left(T s_{\text {turb }}-T e_{\text {turb }}\right) \\
P_{c p r}=q_{\text {mair } c p r} \times c_{p \text { air }} \times\left(T s_{c p r}-T e_{c p r}\right) \\
P_{f}=P_{\text {turb }}-P_{c p r}
\end{gathered}
$$

Finally, Lamquin [14] used a "hybrid" method: the compressor wheel was replaced by a bladeless wheel so that the compressor work equals to zero. Testing in adiabatic conditions, the consequence is that the turbine power (calculated thanks to inlet and outlet temperatures and mass flow) transfers integrally to oil.

The presented study is mainly based on thermodynamic analysis. This choice was made for two reasons:

- The possibility to extend the measured range to high rotational speed

- The possibility to test a turbocharger without any modification

An adiabatic test campaign is performed and the two methods were used to check the correctness of adiabatic criterion. Additionally a third method was tested, as in Vanhaelst [9]: measuring the coast down time of the turbocharger when air feeding is shut off enables the calculation 
of the friction power. This method bases on different equations and also requires TC modifications. Moreover, the measurements values are the sum of friction losses and drag of the turbine wheel. A study on three oil parameters is then performed: oil properties (viscosity and grade), oil inlet temperature and oil inlet pressure.

The turbocharger test rig is first described in the next section. Then experimental systems are presented. An analysis of the results is performed for each studied parameter.

\section{Turbocharger Test Rig Description}

In the used configuration, the turbocharger test rig enables to test turbochargers in static conditions (fig. 1 and 2). A screw compressor $(75 \mathrm{~kW})$ delivers compressed air up to 7.5 bars and with maximum flow rate of $0.24 \mathrm{~m}^{3} / \mathrm{s}$. The compressed air is filtered and its flow is regulated by an electric vane. An electric heater of $192 \mathrm{~kW}$ enables to reach turbine inlet air temperature greater than $500^{\circ} \mathrm{C}$. Finally, air is exhausted outside the test cell by an extractor fan.

The compressor sucks ambient filtered air from the test cell via an electrical heater and a mass flow meter. An electric vane at the outlet of the compressor controls the mass flowing through the compressor and hence the pressure ratio.

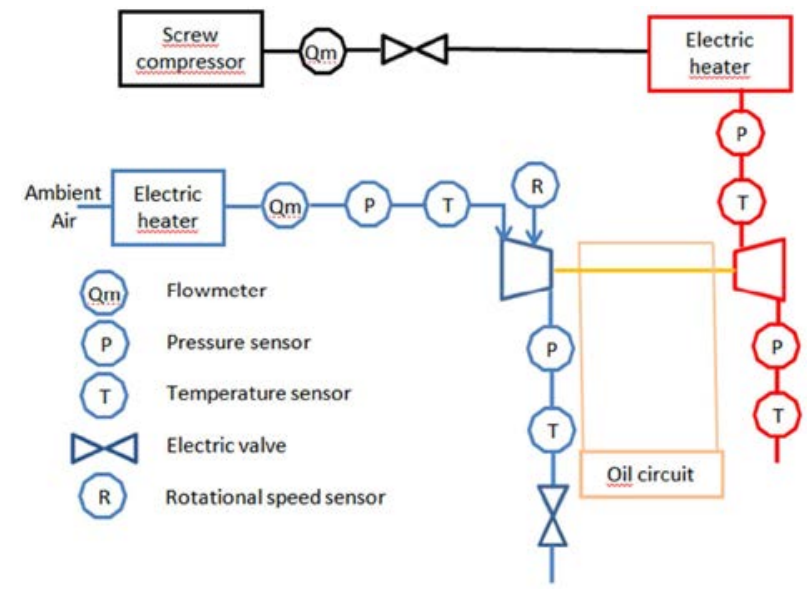

Figure 1. Turbocharger test bench description

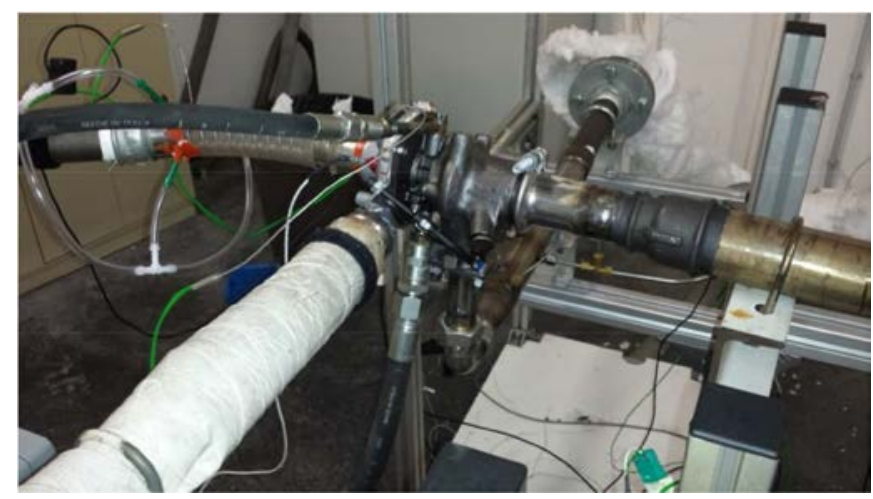

Figure 2. Turbocharger test bench

The oil temperature is also a first order parameter to reach adiabatic conditions. It then has to be precisely regulated. A two way circuit has been developed for adiabatic tests. The oil can be heated or cooled via a bypass system before flowing in the turbocharger at the inlet temperature set point. However, a second cooling device is added to protect the oil pump (in the case of high oil temperatures), see fig. 3.

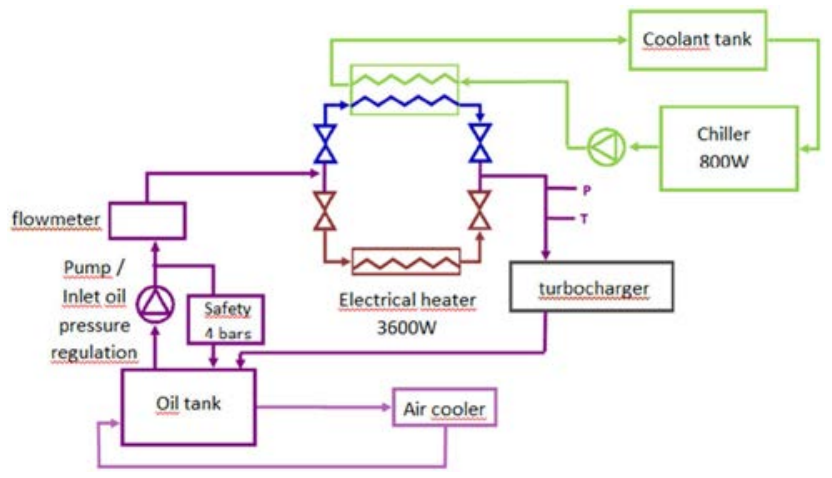

Figure 3. Oil circuit

Thermocouples are used to measure and control (if needed) the temperatures in the inlet and outlet of the turbine and compressor. According to tests, Thermocouples $\mathrm{T}$ type (accuracy $+/-0.1^{\circ} \mathrm{C}$ ) or $\mathrm{K}$ type (accuracy $+/-1^{\circ} \mathrm{C}$ ) are used. The rotational speed is measured via an inductive probe on compressor side (accuracy $+/-0.08 \%$ of full scale). The air mass flows are measured with vortex mass flow meters Optiswirl from Krohne, which range goes from 50 to $550 \mathrm{~kg} / \mathrm{h}$.

Additional T type thermocouples are used at the inlet and outlet of oil circuit in central housing. The outlet temperature is measured in the turbocharger "outlet oil tank", a small cavity in which oil is in liquid phase, see fig. 4 and fig. 5 . Indeed in the outlet part of the turbocharger lubricating system, oil is biphasic (vapor and liquid or air and oil mist). The two phases make the measurement of the oil temperature difficult with thermocouples. Regarding inlet temperature, the thermocouple is set in the screw fixing the oil inlet pipe, cf. fig. 9. This position enables to really measure the oil temperature when entering the turbocharger.

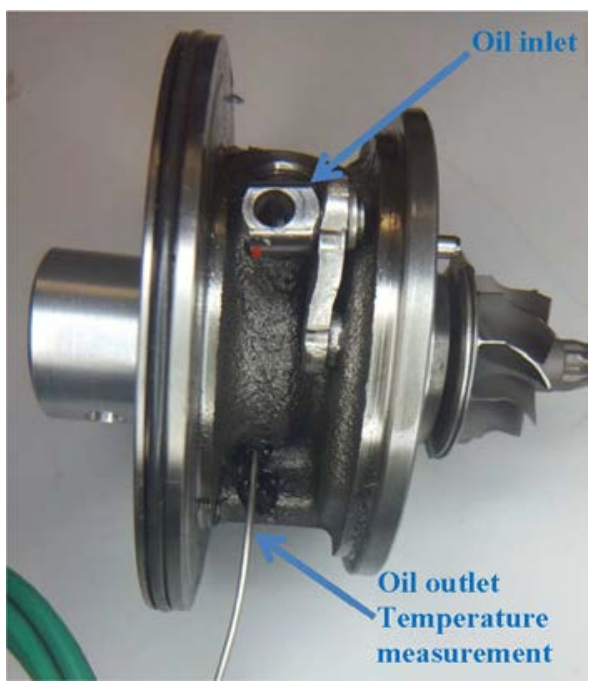

Figure 4. Oil Outlet temperature measurement 


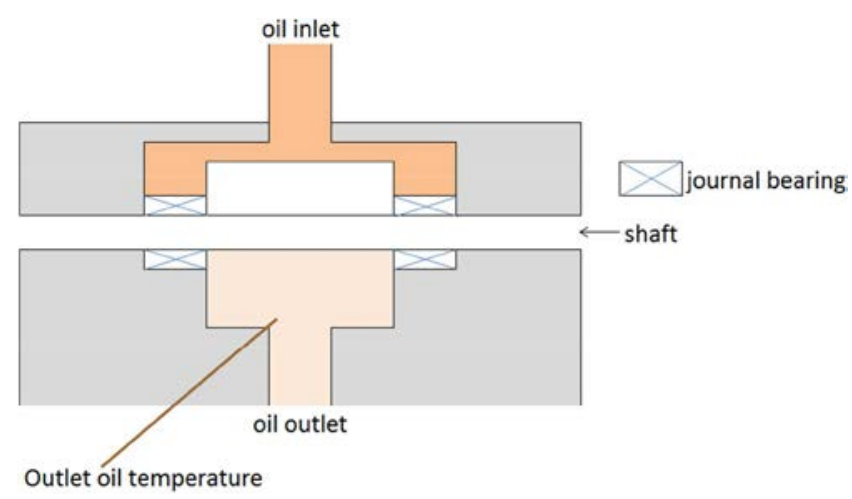

Figure 5. sectional view of the central housing

\section{Test Campaign Procedures}

\subsection{Studied Turbochargers}

Two different turbochargers were used in this study. However both are automotive turbochargers from small Diesel engines. The difference lies in the way to control the boost pressure: first turbocharger is equipped with a VGT, it is called Turbocharger 1. The second one is equipped with a waste gate, and is called Turbocharger 2. They have also slightly different dimensions. The turbocharger 1 is mainly used for this study. For some tests, the turbocharger 2 is also used to confirm and extend the results. The default turbocharger is then Turbocharger 1 .

\subsection{Adiabatic Conditions}

Many studies have already performed tests in quasi-adiabatic conditions [11] \& [12], using most commonly oil inlet temperature and mean turbine and compressor temperatures. To reach adiabatic conditions, it has been chosen to work with mean oil temperature, as in equation (8). This ensures no heat transfer occurs inside the turbocharger between different parts of this device.

$$
\frac{T_{e c p r}+T_{\text {scpr }}}{2}=\frac{T_{e t u r b}+T_{s t u r b}}{2}=\frac{T_{e o i l}+T_{s o i l}}{2}
$$

The turbocharger was fully insulated for these tests to avoid any heat transfer with environment. The measuring points were acquired only when the thermal balance between the three terms of eq. (8) was reached. We defined this balance as a difference between the mean temperatures lower than $1^{\circ} \mathrm{C}$.

\subsection{Validation of the Adiabatic Hypothesis}

To ensure the hypothesis is valid, a test campaign was performed. The regulated temperatures are set so that the criterion from (8) is met, see fig. 6 , for oil inlet temperature. The friction power was then calculated in two ways: based on oil enthalpy variation eq. (4) and compressor and turbine powers difference eq. $(\underline{5}, \underline{6}, \underline{7})$. The two results were compared, see fig. 7. The turbocharger speed was raised up to $220000 \mathrm{rpm}$.

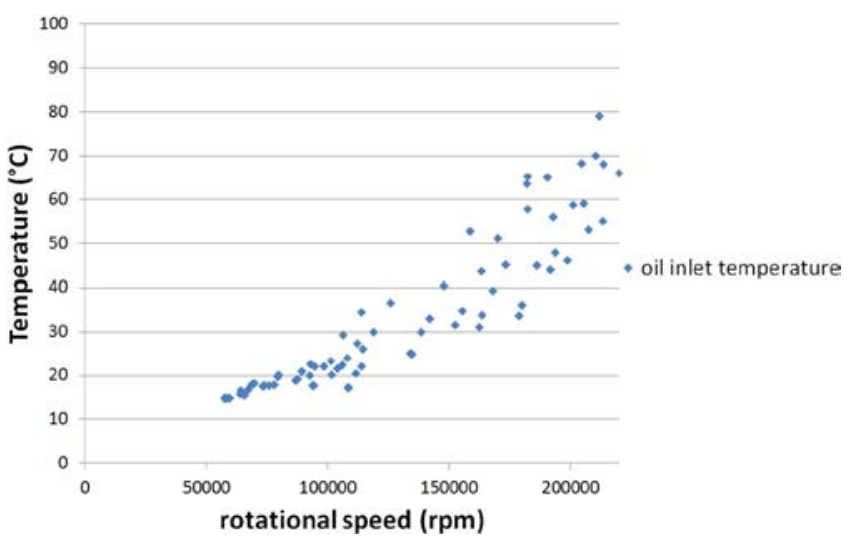

Figure 6. oil inlet temperature vs. TC speed

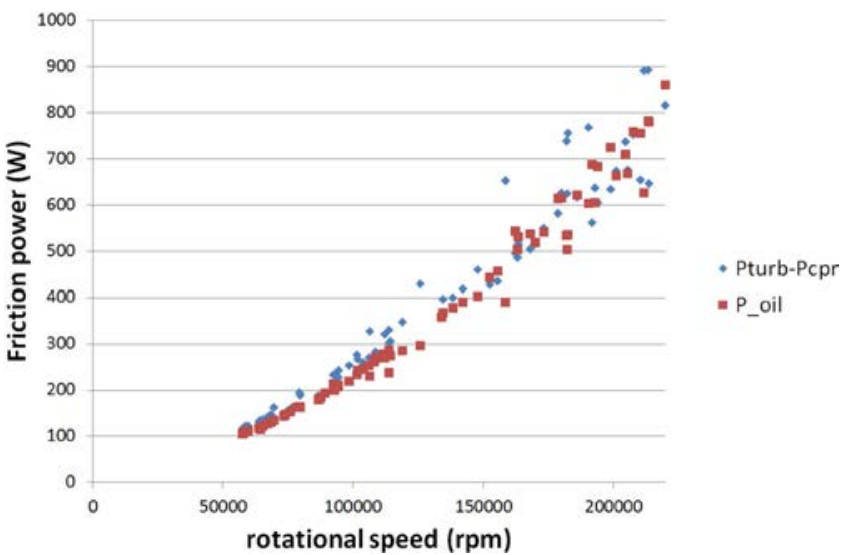

Figure 7. Friction power calculated with two enthalpy variations methods

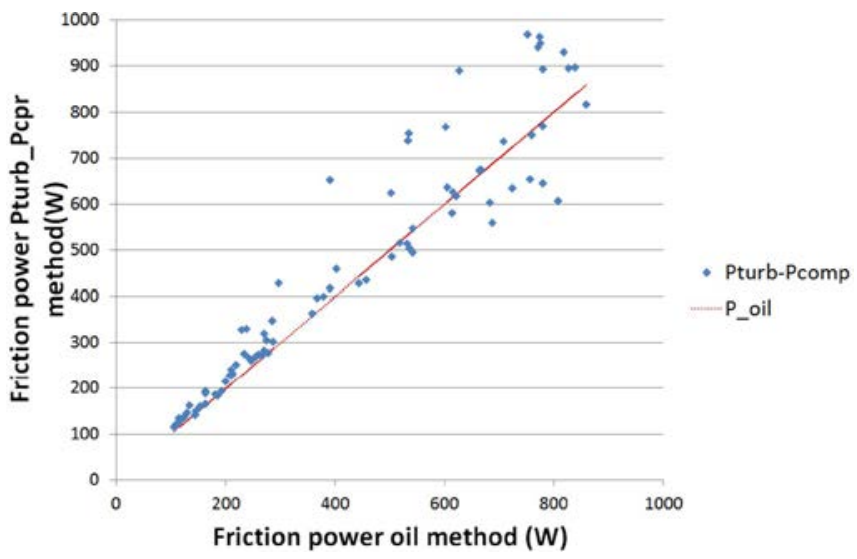

Figure 8. Friction power $\left(\mathrm{P}_{\text {turb }}-\mathrm{P}_{\text {cpr }}\right)$ vs. fretion power via oil power

The two calculated powers $\left(\mathrm{P}_{\text {turb }}-\mathrm{P}_{\text {cpr }}\right)$ and $\mathrm{P}_{\text {oil }}$ are close. Almost $84 \%$ of the points calculated by the difference of powers are included in a $+/-20 \%$ range from oil method corresponding points, see fig. 8 . Some points show a more significant difference but they are always in the same range, which strengthens the confidence in the results, at one and the same time in the adiabatic methodology and in the validity of the results. Indeed, the two calculated powers are obtained from independent physical parameters (air circuit / oil circuit).

In the next sections, the results for adiabatic tests are based on oil enthalpy variation.

NB: the fig. $\underline{6}, \underline{7}$ and $\underline{8}$ are extracted from tests with TC2. 


\subsection{Air Turbocharger Feeding Shut Down}

This method is based on moment of inertia. The friction torque is calculated as in eq. (9). Then we can calculate the friction power as described in eq. (10)

$$
\begin{gathered}
C_{f}=-I \times \frac{d \omega}{d t} \\
P_{f}=\omega \times C_{f}
\end{gathered}
$$

With I the moment of inertia, $\mathrm{C}_{\mathrm{f}}$ the friction torque and $\omega$ the rotational speed. The turbocharger is supplied with pressurized dry air to reach a static point. Then the air supply is suddenly switched off and the turbocharger will gradually decelerate and stop after a certain time. Two phenomena will combine to stop the TC: friction losses and aerodynamic drag of the turbine wheel. In this study, we made the hypothesis that the aerodynamic drag of the turbine wheel has a small effect in comparison with friction losses, as the air is shut off. The turbine housing has been slightly machined to reduce this drag effort.

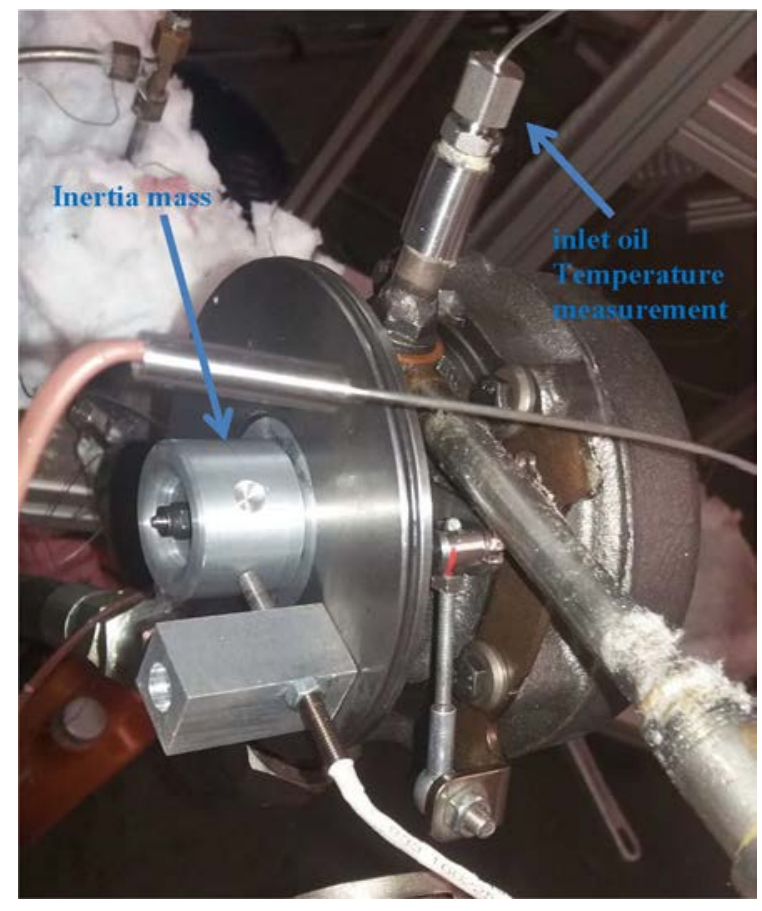

Figure 9. Compressor wheel replacement

Measuring the necessary time to stop enables calculating the friction power thanks to the two above mentioned equations. The main difference with Vanhaelst device [9] is that we do not use additional mechanical device to drive the turbocharger. This enables us more realistic initial conditions but prevents us from measuring the torque applied to the thrust bearing. However, we have removed the compressor wheel and replaced it by a cylinder mass. We have also removed the compressor housing so that the compressor power is zero. The compressor side is shown on fig. 9. A mark is made on the cylinder to be able to measure the rotational speed. This one is as small as possible so that the cylinder balance is maintained at the tested TC speeds. The used sensor is the same as previously but is calibrated for a single blade wheel. The mass and the dimensions of this device will lead to its moment of inertia. The basis turbocharger is the same as for the previous test campaigns. The mass of the new wheel is chosen bigger than the original compressor wheel so that the coast down duration is longer. This enables more precise measurements and also benefits to the reliability of the experimental system. At last, the balance of this wheel was tested.

The signals recording frequency is set to $10 \mathrm{~Hz}$, which allows to see the studied phenomena and limits the data files size. However a signal treatment is necessary so that the rotational speed derivative can be used to calculate the friction torque. A Butterworth filter is used and a zero phase digital filtering is applied by processing the signal in both the forward and reverse direction. An example is shown fig. 10. Because of our experimental setup, the maximum rotational speed was limited to $100000 \mathrm{rpm}$. Moreover, one has to ensure that the decreasing slope is significant enough so that the derivative function gives relevant information.

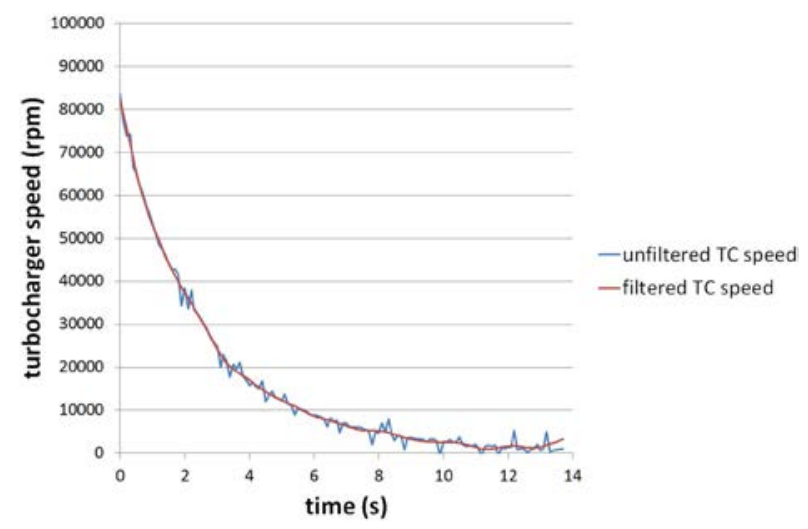

Figure 10. Unfiltered and filtered speed signal during turbocharger stop

\subsection{Oil grade}

Three different oil grades were tested during the campaign. The grades were chosen to ensure different behaviors. The SAE grades of the oils are:

$$
\begin{array}{ll}
\text { - } & 0 \mathrm{~W} 30 \\
\text { - } & 10 \mathrm{~W} 40 \\
\text { - } & 10 \mathrm{~W} 60
\end{array}
$$

NB: the different used oils are commercial ones. Hence datasheet from manufacturers are available. We based our dynamic viscosity curve calculation on manufacturer data (oil viscosity for $\mathrm{T}=40^{\circ} \mathrm{C}$ and $\mathrm{T}=100^{\circ} \mathrm{C}$ ). As Deligant [15], we determine the viscosity using the Vogel equation (11).

$$
\mu=a \times e^{\left(\frac{b}{T-c}\right)}
$$

The three tuning coefficient $\mathrm{a}, \mathrm{b}$ and $\mathrm{c}$ can either be found on internet database or calculated with a curve fitting tool. The calculated viscosity is shown in fig. 11 . 


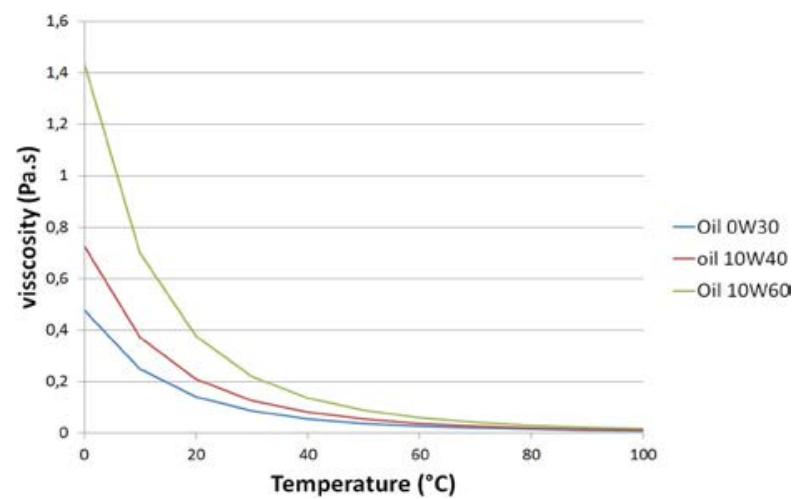

Figure 11. Oil dynamic viscosity vs. oil temperature for the three studied oil grades

In our tests, we have defined an oil inlet viscosity, based on oil inlet temperature, an oil outlet viscosity, based on outlet oil temperature. At last, the viscosity is the mean value of inlet and outlet viscosities.

\section{Oil Properties Influence}

The first study focuses on the oil itself and the role of its grade (oil chemical properties). Related to it the viscosity represents the first order parameter and varies in huge range. The influence of this viscosity on the friction losses is also studied.

Adiabatic tests were performed on turbocharger 1 with the three oils, applying condition of (8) and the friction power is calculated for each, according to (4), see fig. 12. Additionally, tests were performed with turbocharger 2 and different oil grades. Results are similar as those of turbocharger 1 and are not presented here.

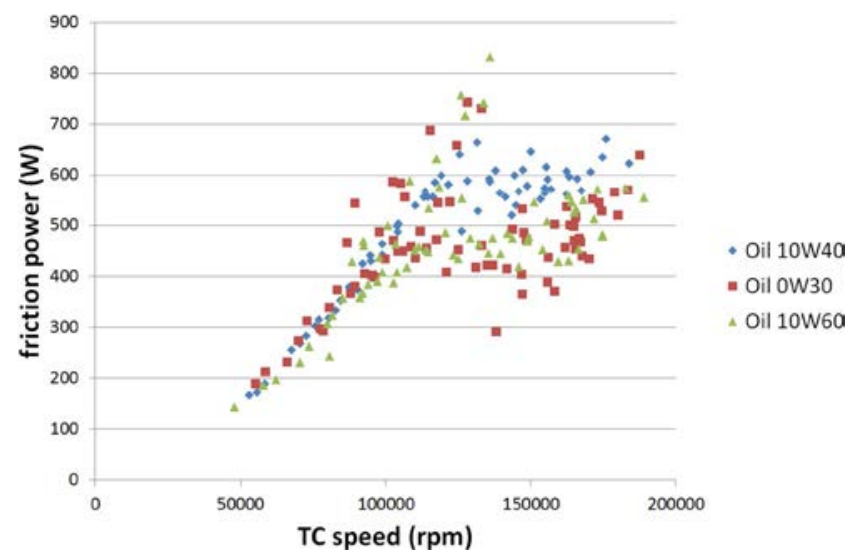

Figure 12. Friction power vs. TC speed for the three studied oil grades

Firstly, we can notice that the power seems to be independent of oil grade and viscosity. This is an unexpected result, as one could imagine that the most viscous oil will generate higher friction power. The second point is that the friction power grows linearly with turbocharger speed until 100k rpm. For higher rotational speeds, it is still growing but there appears to be one or several other influence parameters.

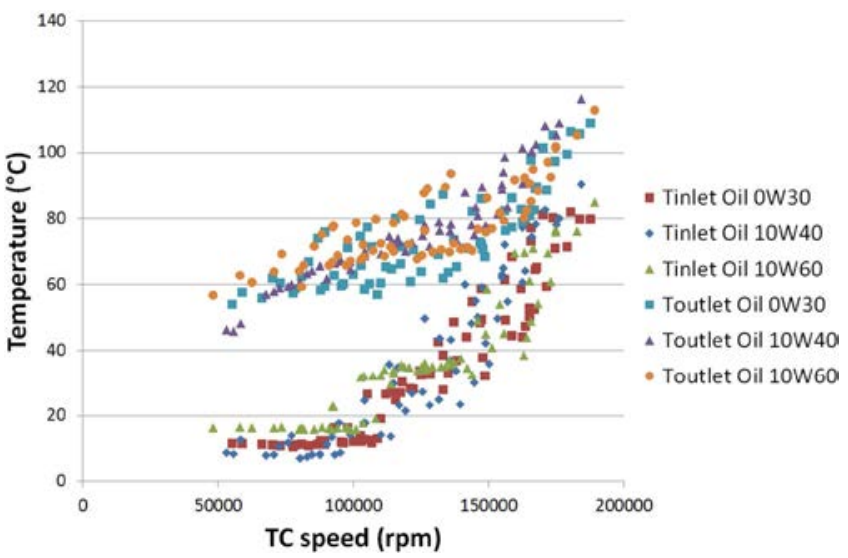

Figure 13. Oil inlet and outlet temperatures for the three studied oil grades

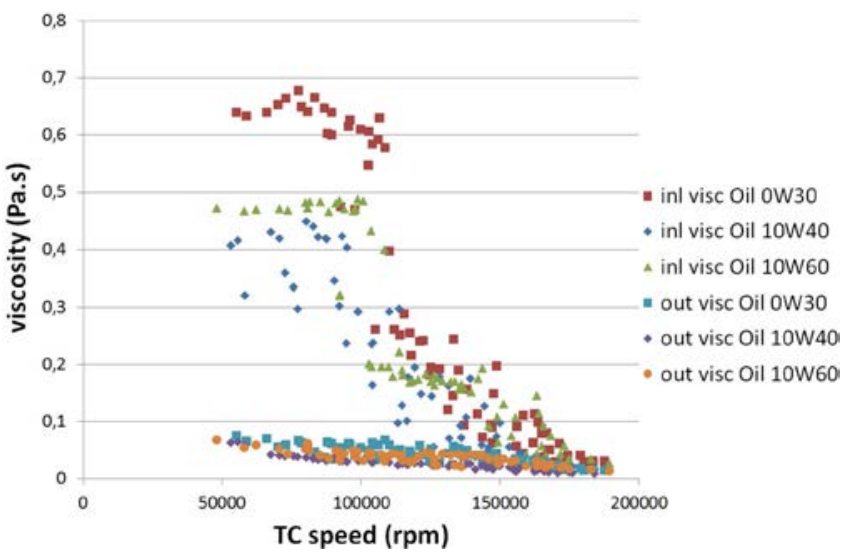

Figure 14. Inlet and outlet viscosities for the three studied oil grades

The viscosity can be calculated for oil inlet and outlet, see fig. 13 . The inlet temperatures are fixed to fulfill the adiabatic criterion. We can notice that the most viscous oil (10W60) has to be more heated to ensure the criterion validity, especially for low TC speeds. At higher values (above 100k rpm), the inlet temperatures are close for the three grades. Regarding the outlet temperatures the values are close to each other for the whole speed range. The corresponding viscosities are drawn on fig. 14. The temperature of oil passing through the bearings is most probably close to the outlet oil temperature. A bearing oil temperature calculation has been defined by Serrano \& al. [11] also based on this assumption. Hence the local viscosity in the bearing is close for the three oil grades. This could explain the independence of friction losses with oil grade which can be observed in the fig. 12 .

\section{Oil Inlet Temperature}

All the test campaigns of this section are performed with TC1 and oil 10W40. The tests of this campaign have been performed with constant inlet oil pressure of 2 bars. 


\subsection{Adiabatic Method}

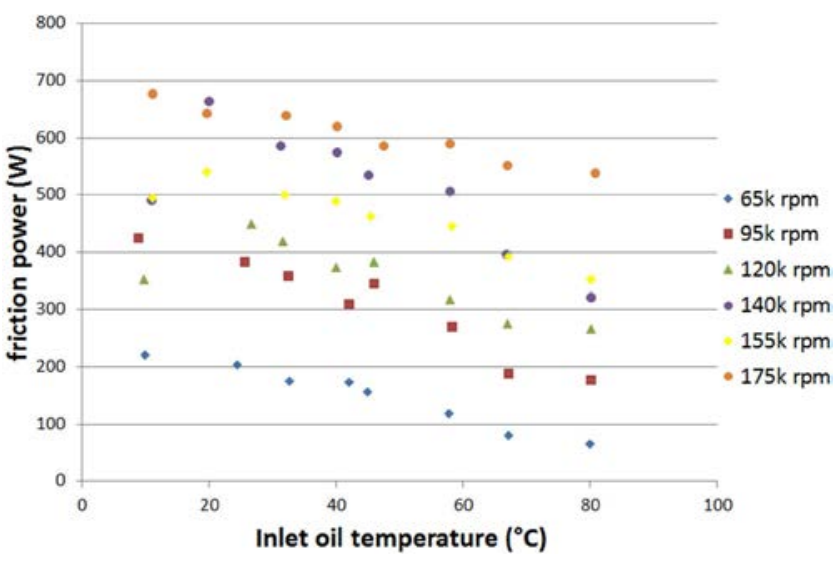

Figure 15. Friction power for different TC speeds

The friction power calculation is based on eq. (4). Firstly, we can notice that the friction power is almost always increasing with the TC speed (for a given oil inlet temperature), see fig. 15. We can also see that this power decreases when oil inlet temperature rises for a given TC speed level. However the power reduction is quite limited. It could be roughly modeled by a linear equation with constant negative slope. We can notice it is far from variations of viscosity changes between $15^{\circ} \mathrm{C}$ and $80^{\circ} \mathrm{C}$, see fig. 11 (oil $10 \mathrm{~W} 40$ ). Indeed, the viscosity of this oil is divided by 13 for oil temperature between $15^{\circ} \mathrm{C}$ and $80^{\circ} \mathrm{C}$. A phenomenological analysis could explain this as follows. An increase in oil inlet temperature leads to an increase in oil flow rate through the bearing, see fig. 16. This increase counteracts the effect of reduced viscosity on friction.

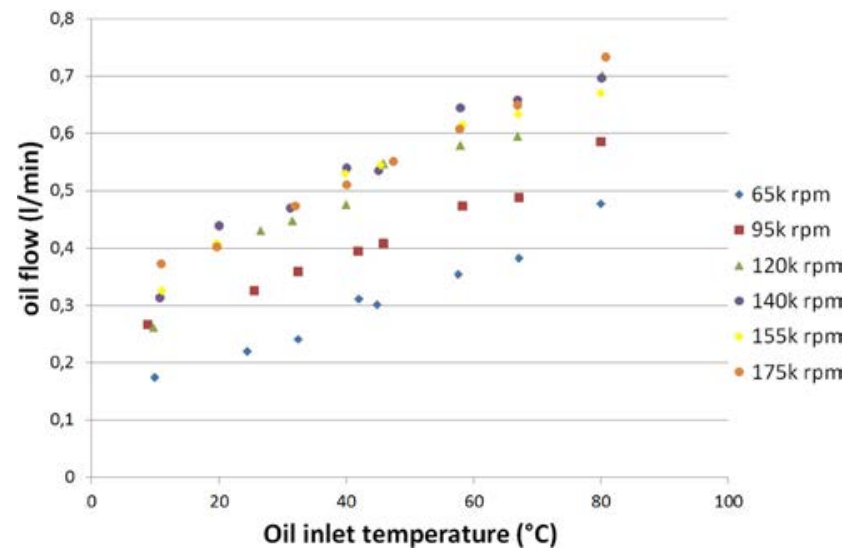

Figure 16. Oil flow vs. oil inlet temperature for different turbocharger speeds

\subsection{Turbocharger Stop}

This method is also used to study the influence of oil temperature on friction power, which calculation is governed by inertia moment based equations, eq. (9) \& (10). We can see on fig. 17 that the stop time is longer for high oil temperatures, which is expected if friction losses are reduced in comparison with cold oil temperature.

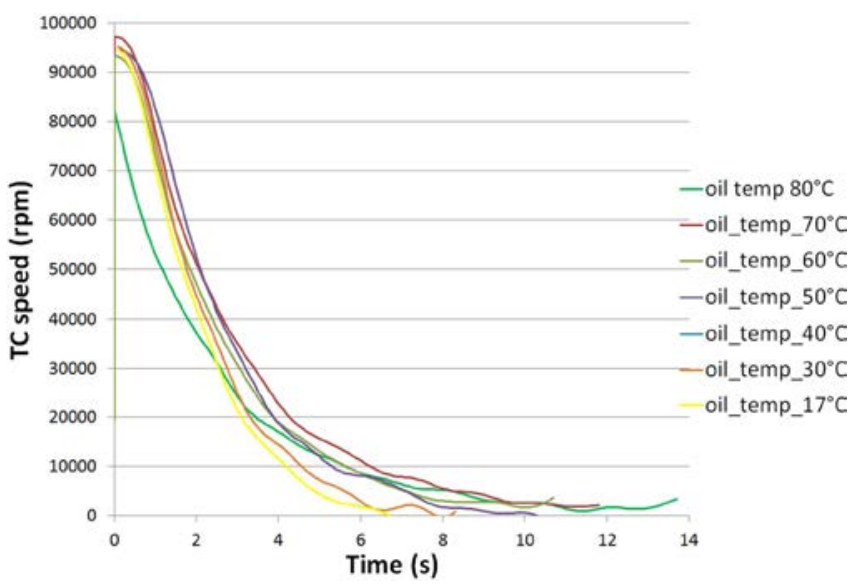

Figure 17. Filtered speed signal during turbocharger stop for different oil temperatures

The friction power is then calculated. Fig. 18 shows the evolution of friction power vs. oil inlet temperature for different rotational speeds. We can observe the same trends as previous campaign. The friction power decreases when the oil temperature increases. Moreover the decrease seems to be quite linear with a similar slope for all TC speeds. For a given oil temperature, the friction power increases along with rotational speed.

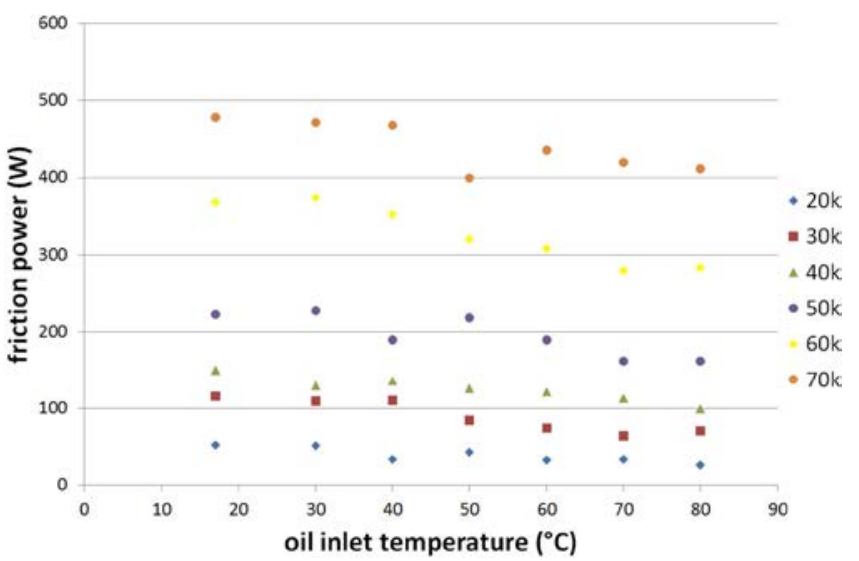

Figure 18. Friction power vs. oil inlet temperature for different TC rotational speeds

\subsection{Comparison of the Two Methods}

We can notice that the results obtained thanks to the two methods give similar trends for low TC speeds. The friction power decreases with oil inlet temperature increase on a TC speed. The decrease is almost linear and the slopes of all TC speeds seem to be close. However we can notice a difference in the absolute value of the friction power on the $60-65 \mathrm{k} \mathrm{rpm}$ speed, but the order of magnitude is the same. The system differences could explain the gap: in the turbocharger stop method, the compressor housing is removed and the wheel is replaced by inertia mass. This can change the axial force on thrust bearing which has an impact on friction losses value, cf. Deligant [4] \& Vanhaelst [9]. Moreover the air feeding shutoff can change the force balance on thrust bearing too. Additionally, the 
turbine wheel consumes power during the coast down of the TC. The adiabatic method enabled us extending the measurements to high speeds and thus covering a large range of turbocharger life conditions. Moreover, the adiabatic hypothesis has been validated, see fig.7. Hence we will give priority to the adiabatic method. The second could be used to confirm the trends and also to check the TC behavior for very low speeds. A way to extend the first method to very low TC speeds would be to use additional flow meters, which range would be adapted to these small flows.

\section{Oil Inlet Pressure}

The oil inlet pressure value is regulated. The tested range goes from 0.4 bars to 3 bars. All mentioned pressure values are gauge values. The tests were conducted on both systems (conventional adiabatic test bench and air feed stop system).

\subsection{Adiabatic Tests}

The friction power is calculated according to eq. (4). Three turbocharger speeds are tested: $55 \mathrm{k} \mathrm{rpm}, 105 \mathrm{k} \mathrm{rpm}$ and $150 \mathrm{k} \mathrm{rpm}$. Eight values of oil inlet pressure between 0.4 and 3 bars are tested. Some test cases (couple: TC speed, oil pressure) were not performed or saved because of stabilization matters. However at least six out of eight possible points are measured for each speed level.

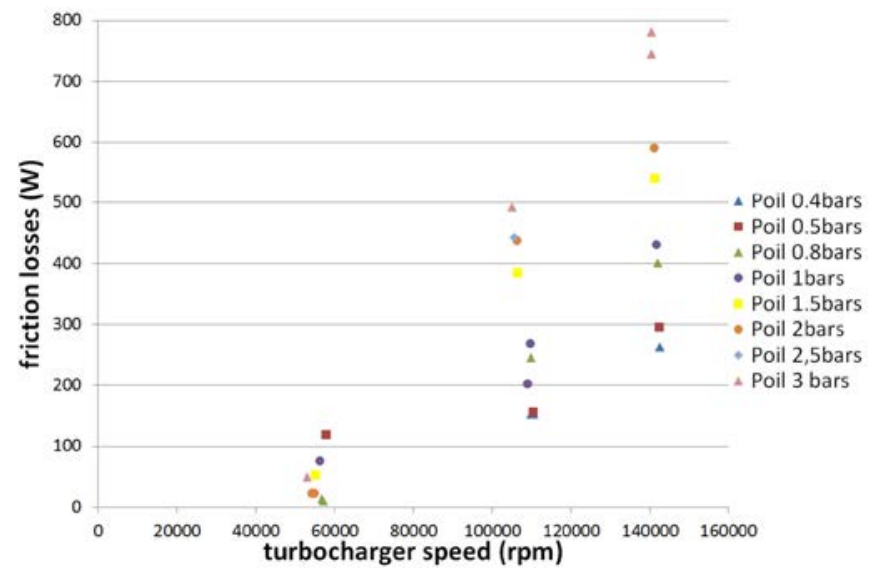

Figure 19. Friction power vs. turbocharger speed for different inlet oil pressures

Fig. 19 shows the friction losses vs. the turbocharger speed. It appears that for low speed, the oil inlet pressure has no or very limited impact on the power losses variations. Indeed, no regular evolution can be noted and the maximum difference is about 100W. For high TC speed, this difference will grow and the frictions can be multiplied by at least three times for the same TC speed. This result is in accordance with Vanhaelst [9] results, which were limited to 90k rpm. Lamquin [14] showed also a threshold but higher than the value of the present study. The fig. 19 shows that this phenomenon grows along with TC speed. If we focus on TC speeds, we can observe the influence of oil pressure in stabilized TC conditions. This is shown on fig. 20.

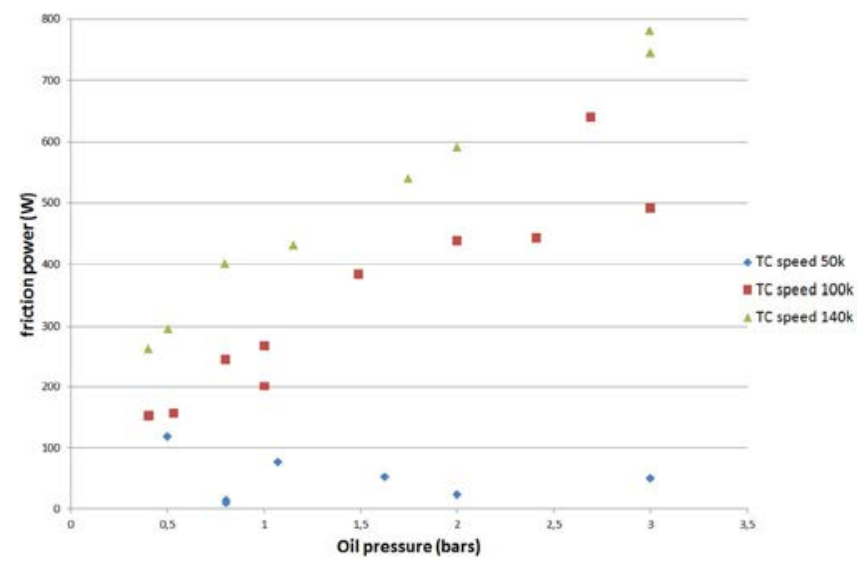

Figure 20. Friction power vs. oil pressure for three turbocharger rotational speeds

We can observe again that the oil pressure does not influence the friction losses for low turbocharger speed $(50 \mathrm{k} \mathrm{rpm})$. For higher values, the influence is clear and could be considered as linearly growing with oil pressure. Moreover, the slope of the trend curve line seems to increase with the turbocharger speed. The behavior observed in fig. 19 can be seen also regarding the volumetric oil flow in the turbocharger, see fig. 21. The oil flow rate strongly increases by almost a factor of 5 . The consequence is a decrease of oil temperature difference between TC inlet and outlet. Fig. 22 illustrates this phenomenon. This will in turn result in a lower oil temperature in the bearings and then, the viscosity will be slightly higher. This statement is in agreement with Vanhaelst [9] results. However fig. 22 shows that the scale is much more limited than the flow variation. The combination of the phenomena results then in a friction power increase.

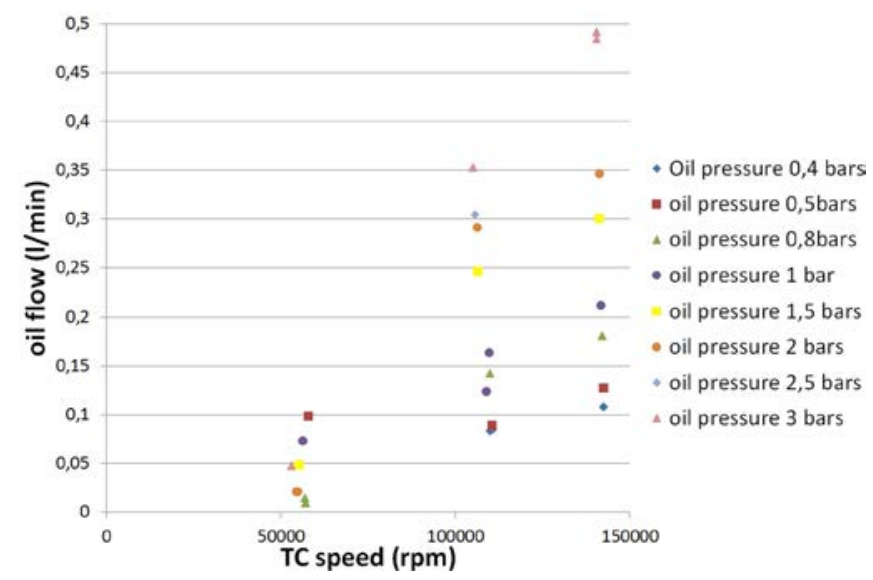

Figure 21. Oil flow vs. turbocharger speed for different oil inlet pressures

Comparing fig. 19 and 21 , we can plot the friction losses vs. the oil flow to check the influence of this variable on friction losses, see fig. 23 . 


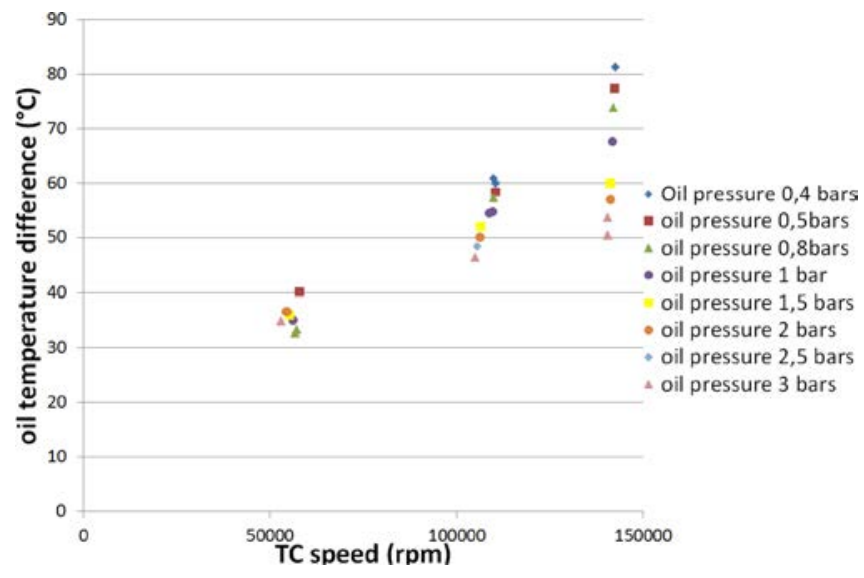

Figure 22. Oil outlet and inlet temperature difference vs. turbocharger speed for different oil inlet pressures

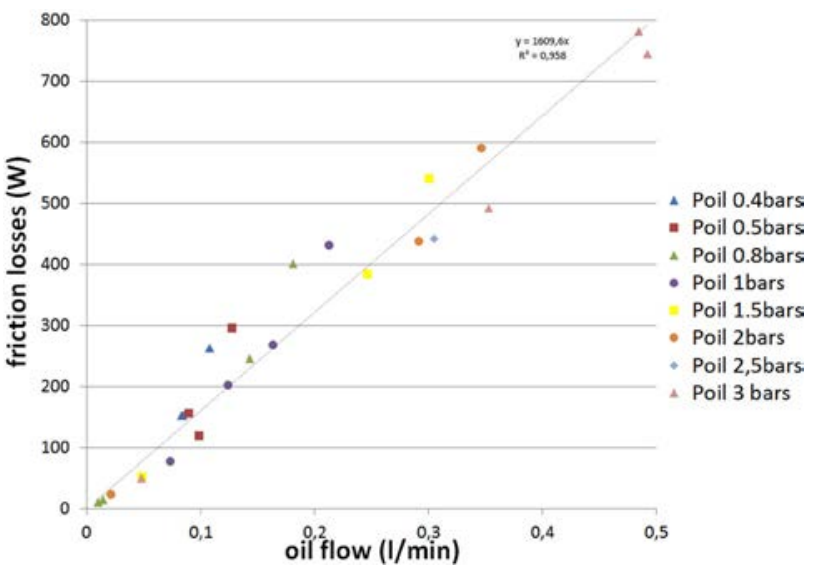

Figure 23. Friction losses vs. oil flow for different oil inlet pressures

It appears that the oil flow is a key parameter and should be used instead of oil inlet pressure in a model of friction losses.

\subsection{Turbocharger Stop}

The procedure was run with different oil inlet pressures, from 0.8 bars to 3 bars. The initial oil pressure was set to the set point value. However, during the turbocharger coast down phase, the inlet pressure increase presents an overshoot value before going back to the set point, see fig. 24. This is due to the oil pump itself: this pump regulates the oil flow based on turbocharger oil inlet pressure. When air feed is suddenly shut off, the effective section decreases. Hence the oil flow decreases also, generating an increase of pressure. This point could be reduced by using heavier inertia mass so that the coast down dynamic is reduced or by a specific discharge circuit. This phenomenon can be observed for different initial oil pressures, see fig. 24. The overshoot occurs for every initial oil pressure and seems even higher for high pressures.
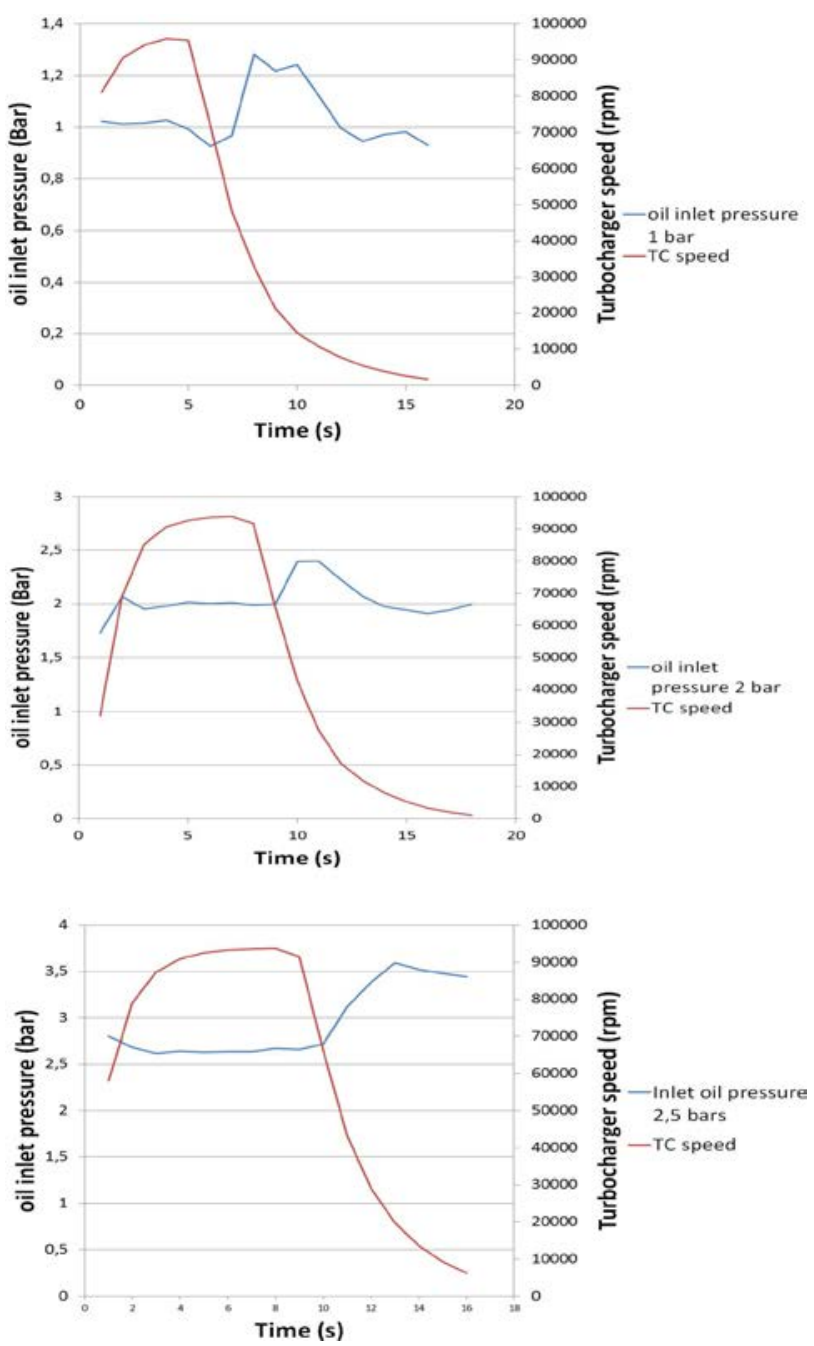

Figure 24. Oil pressure evolution during TC deceleration for different initial oil pressures

Tests were conducted for gauge pressure range from 0.8 bars to 3 bars and for TC speeds from 10k to $75 \mathrm{k} \mathrm{rpm}$, see fig. 25 . It appears the friction power depends on the turbocharger speed. The influence of oil pressure cannot be identified with these tests. This is due to the TC speed tested range and is coherent with results from first method. It seems that the non-dependency goes up to $75 \mathrm{k} \mathrm{rpm}$. Then this test can confirm the statement about low speeds from former paragraph. Moreover the numerical values are different, due to the chosen inertia mass.

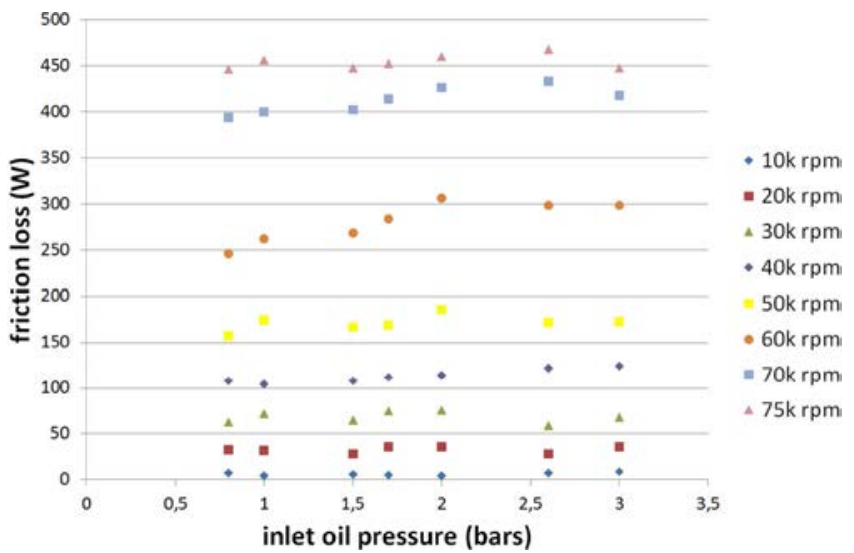

Figure 25. Friction losses vs. oil inlet pressures for different rotational speeds 


\section{Summary/Conclusions}

In this paper, an experimental campaign has been performed to determine the mechanical losses of a turbocharger. Three methods were used. The first and second ones lie on adiabatic tests to be able to neglect the heat transfers and only focus on friction losses. The adiabatic hypothesis is validated and the method based on oil enthalpy variation gives access to a large range of turbocharger speed, from $50 \mathrm{k} \mathrm{rpm}$ to $250 \mathrm{k} \mathrm{rpm}$. However, the adiabatic method requires complex test stand as the three inlet temperatures (compressor, turbine and oil) must be regulated to fulfill the eq. (8). Moreover, the test campaign takes more time than the third method as the thermal balance must be reached. The third method is based on inertia moment and consists in measuring the coast down time of a turbocharger formerly supplied with pressurized air. The advantage of this method is that it avoids intrusive (inlet and outlet) oil temperature measurements. This method can also be used to determine the influence of external parameters (for instance: oil inlet pressure and temperature) but the obtained quantitative values are not equal to the ones of the first methods, even if they are in the same range.

Moreover, the compressor wheel replacement (by a mass cylinder) and the air shut off on turbine side can change the behavior of the bearings and the balance of the mass has to be checked carefully. At last the wheel drag cannot be measured separately in our lab and we could not validate the hypothesis on negligible drag effort. Hence, the method based on adiabatic tests and oil enthalpy variation is selected.

The test campaign has focused on three parameters: oil grade, oil inlet temperature and oil inlet pressure. Firstly, the results on oil grade tests show that the classical available oil temperatures cannot be used to estimate the viscosity of the oil in the bearings. Frequently used models are based on proportional relation between friction losses and viscosity. The latter should be calculated from the in-bearing oil temperature, which has then to be modeled. An example of such a temperature calculation is presented in [11]. Secondly, the oil inlet temperature is an important influence factor, along with TC speed and should be taken into account. At last, the oil inlet pressure has a role only from a turbocharger speed threshold. This one has to be determined. This study has enabled to define reliable measurement procedures and to generate a database. This will be the basis data to develop and validate a turbocharger friction model designed for integration in 0D/1D engine model. It has enabled to identify some key parameters, as oil flow rate and oil temperature at bearing stages, and some trends to define the equations linking these parameters to the friction losses in the model. Moreover, a tuning methodology has to be defined, as simple as possible, so that expert and non-expert users can use the model. The whole package will be tested on other turbochargers to check the portability on other types of turbochargers (e.g.: water cooled SI engine turbocharger).

\section{References}

1. Zhang, Q., Duda, T., Burke, R., Akehurst, S. \& al., "Experimental and analytical investigation of implementing a ball bearing turbocharger on a production Diesel engine", 11th International Conference on Turbochargers and Turbocharging, 13-14 may 2014, pages 149-162, doi: $\underline{10.1533 / 978081000342.149}$
2. Watson, N., Janota, M. S., "Turbocharging the Internal Combustion Engine", Macmillan Education Ltd, ISBN 0-33324290-4

3. Serrano, J., Olmeda, P., Tiseira, A., García-Cuevas, L. et al., "Importance of Mechanical Losses Modeling in the Performance Prediction of Radial Turbochargers under Pulsating Flow Conditions," SAE Int. J. Engines 6(2):729-738, 2013, doi: 10.4271/2013-01-0577.

4. Deligant, M., Podevin, P., Descombes, G., "Experimental identification of turbocharger mechanical friction losses", Volume 39, Issue 1, March 2012, Pages 388-394, doi: 10.106/j. energy.2011.12.049

5. Cormerais, M., Hetet, J.F., Chessé, P., Maiboom, A., "Heat transfers charaterizations in a variable geometry turbocharger: experiments and correlations", proceedings of ICE 2006: ASME International Combustion Engine Division 2006 Spring Technical Conference, May 8-10, 2006 Aachen, Germany

6. Salameh, G., Chesse, P., Chalet, D., and Talon, V., "Experimental Study of Automotive Turbocharger Turbine Performance Maps Extrapolation," SAE Technical Paper 201601-1034, 2016, doi:10.4271/2016-01-1034.

7. Shi, F. and Deng, D., "An Analysis for Floating Bearings in a Turbocharger," SAE Technical Paper 2011-01-0375, 2011, doi:10.4271/2011-01-0375.

8. Podevin, P., Clenci, A., Descombes, G., «Influence of the lubricating oil pressure and temperature on the performance at low speeds of a centrifugal compressor for and automotive engine», Applied Thermal Engineering, doi : 10.1016/j. applthermaleng.2010.08.033

9. Vanhaelst, R., Kheir, A. Czajka, J. "A systematic analysis of the friction losses on bearings of modern turbocharger", Combustion Engines, 2016,164(1), 22-31, ISSN 2300-9896

10. Sjöberg, E., "Firction Characterization of Turbocharger bearings", Master of Science Thesis MMK 2013:06 MFM49

11. Serrano, J.R., Olmeda, P., Tiseira, A., Garcia-Cuevas, L.M., and Lefebvre, A., "Theoretical and experimental study of mechanical losses in automotive turbochargers", Energy, 55,888-898.

12. Marelli, S., Gandolfi, S., and Capobianco, M., "Experimental and Numerical Analysis of Mechanical Friction Losses in Automotive Turbochargers," SAE Technical Paper 2016-011026, 2016, doi:10.4271/2016-01-1026.

13. Payri, F., Serrano, J.R., Olmeda, P. Paez, A. \& al., «Experimental Methodology to Characterize Mechanical Losses in Small Turbochargers", Proceedings of ASME Turbo Expo 2010: Power for Land, Sea and Air, GT2010, June 14-18, 2010, Glasgow, UK

14. Lamquin, T., Gjika, K., 2009, "power losses identification on turbocharger hydrodynamic bearing systems: test and prediction",. Proceedings of ASME Turbo Expo 2009, Paper GT2009-59599, June 8-12, 2009, Orlando, FL USA.

15. Deligant, "Caractérisation Numérique et Expérimentale des Performances d'un Turbocompresseur Automobile aux Bas Régimes de Rotation”, Thèse de Doctorat, 07/04/2011 


\section{Contact Information}

Nicolas PERROT

TSM Team : "Thermodynamique des Systèmes Moteurs"

LHEEA Laboratory : « Laboratoire Hydrodynamique, Energétique et Environnement Atmosphérique »

Ecole Centrale Nantes

BP92101, Nantes Cedex 3, France

nicolas.perrot@ec-nantes.fr

Phone: +33240371505

\section{Acknowledgments}

The authors wish to acknowledge Renault, Siemens and Ecole Centrale de Nantes, members of the industrial chair financing this project. The industrial chair is entitled "Modelisation système pour le contrôle et la mise au point des moteurs à combustion interne": system modeling for the control and calibration of internal combustion engines.
Abbreviations
c - Specific heat $(\mathrm{J} / \mathrm{kg} / \mathrm{K})$
cp - heat capacity $(\mathrm{J} / \mathrm{kg} / \mathrm{K})$
C - Torque (Nm)
f - friction

I - Moment of Inertia (kg. $\left.\mathrm{m}^{2}\right)$

k - kilo

$\boldsymbol{\mu}$ - Oil dynamic viscosity (Pa.s)

$\boldsymbol{\eta}$ - efficiency

P - Power (W)

qm - Mass flow $(\mathrm{kg} / \mathrm{s})$

T - Temperature $\left({ }^{\circ} \mathrm{C}\right)$

Te - Inlet Temperature $\left({ }^{\circ} \mathrm{C}\right)$

Ts - Outlet Temperature $\left({ }^{\circ} \mathrm{C}\right)$

$\boldsymbol{\omega}$ - Rotational speed (rad.s $\left.{ }^{-1}\right)$

cpr - compressor

HIL - Hardware In the Loop

isent - isentropic

LCV - Light Commercial Vehicle manuf - manufacturer

mec - mechanical

MIL - Model In the Loop

SI - Spark Ignition

TC - TurboCharger

turb - Turbine

VGT - Variable Geometry Turbine 